\title{
LACK OF HABITAT CHOICE IN A NATURAL POPULATION OF DROSOPHILA SUBOBSCURA
}

\author{
W. D. ATKINSON* and J. A. MILLER† \\ - Dept. of Zoology, University of Edinburgh, West Mains Road, Edinburgh, EH9 3JT; and \\ + Dept. of Pure and Applied Zoology, The University, Leeds, LS2 9JT
}

Received 3.ix.79

\begin{abstract}
Summary
Microgeographic genetic differentiation maintained by individual habitat choice has previously been described in Drosophila persimilis. In this study individual preferences for different habitats, times of day, and baits were investigated in $D$. subobscura using mark-release-recapture methods. No evidence was found for the occurrence of individual habitat choice, and this is consistent with the fact that the inversion polymorphism of $D$. subobscura is relatively inflexible and does not respond quickly to the environment. Individuals did not tend to prefer different times of day, but there was some suggestion of feeding or breeding site fidelity, with individuals returning to familiar baits.
\end{abstract}

\section{INTRODUGTION}

Recentuy, Taylor and Powell (1977) have demonstrated microgeographic genetic variation in a population of Drosophila persimilis at Mather, California. There were significant differences between the allozyme frequencies and gene arrangements of flies collected from ecologically distinct areas whose centres averaged only $335 \mathrm{~m}$ apart. Given the high rate of dispersal of $D$. persimilis, it was impossible to account for the variation by various models of drift or selection. It could, however, be explained if flies with different genotypes preferred different habitats. This was confirmed (Taylor and Powell, 1978) by mark-release-recapture experiments which showed that $D$. persimilis and $D$. pseudoobscura tend to return to their area of origin, or to an ecologically similar area, when transplanted away. If the phenomenon of individual habitat choice was of general occurrence it would have important implications for the maintenance of genetic variation. Different genotypes could select the microhabitat in which they were most fit, and variation could be maintained without heavy genetic load (Taylor, 1975).

$D$. subobscura is a European species which is closely related to the North American species $D$. persimilis and $D$. pseudoobscura. Krimbas and Alevizos (1973) have presented evidence of microgeographic genetic variation in a Greek population of $D$. subobscura, so individuals of this species might be expected to exhibit habitat choice. We investigated this in a population of D. subobscura at Adel Dam, a mixed woodland of $50 \mathrm{ha}, 8 \mathrm{~km}$ north of the centre of Leeds, England. The woodland is described by Shorrocks (1975).

Taylor and Powell (1978) suggested that light level or moisture or both were important cues for $D$. persimilis and $D$. pseudoobscura in selecting their correct habitat. Since these variables change quite predictably during the day, there is the possibility that different genotypes might select different 
times of the day to be active, as do the different morphs of the butterfly, Colias eurytheme (Hovanitz, 1953). Daily rhythms of flight activity are well documented for $D$. pseudoobscura (Mitchell and Epling, 1951) and D. subobscura (Dyson-Hudson, 1956), both species showing peaks of activity in the early morning and late evening, with little or no activity in the middle of the day. If the morning and evening peaks consist of distinct populations it has serious consequences for measurements of population density and effective population number (Crumpacker and Williams, 1973; Begon, 1976, 1977, 1978; Powell et al., 1976). Accordingly, we investigated temporal selection as well as habitat choice.

\section{Methods}

We selected two pairs of sites at Adel Dam, each pair consisting of a dark habitat adjacent to a lighter one. Illumination was measured in each habitat as reflected light $50 \mathrm{~cm}$ above a white sheet spread on the ground. Habitat A (Illumination-310 lx) consisted of mature beech (Fagus sylvatica) and alder (Alnus glutinosa), with little undergrowth and a closed canopy. This was next to habitat B $(900 \mathrm{~lx})$, a large open and marshy clearing, containing a few young alder and willows (Salix sp.). Habitat C (340 lx) was dominated by mature oak (Quercus petraea) and sycamore (Acer pseudoplatanus), with a good growth of Rhododendron ponticum below, and a closed canopy. Next to it was habitat D (1000 lx), an open stand of young birch (Betula pendula) bordering a small lake.

During 1978 and 1979 we carried out four separate mark-releaserecapture exercises. Habitats A and B were used in May 1978 and July 1979, and habitats $C$ and D were used in June 1978 and September 1978. On each occasion traps baited with fermenting banana, malt or "Guinness" were put out at one site in each habitat. The sites in habitats A and B were $50 \mathrm{~m}$ apart, and the sites in habitats $\mathrm{C}$ and $\mathrm{D}$ were $100 \mathrm{~m}$ apart. These distances are rather smaller than those used by Taylor and Powell (1978) but average dispersal rates in $D$. subobscura are estimated to be only $40 \mathrm{~m}$ per day (Begon, 1976) compared with rates for D. pseudoobscura of around $200 \mathrm{~m}$ per day (Crumpacker and Williams, 1973; Dobzhansky and Powell, 1974; Powell et al., 1976), so the distances are thought to be equivalent. Flies captured in the two habitats were marked with different coloured fluorescent dusts and released well before the end of the evening activity period, half way between the two trapping sites. On the next day flies were trapped in the same two habitats, examined under a dissecting microscope for the presence of marks, and identified to species. On some occasions when few flies were recaptured on the second day, the flies were again marked according to habitat and released as on day 1 . This increased the number of marks available for recapture on subsequent days.

Usually the same baits were put out in a given habitat for both capture and recapture, or else the baits were remixed to prevent any effect of bait on habitat choice. However, in June 1978, in order to test the effect of baits, they were swapped between capture and recapture. The set of baits used for capture in habitat $\mathrm{C}$ were used for recapture in habitat $\mathrm{D}$ and vice versa. This seemed to modify the results, so during July 1979 we tested whether flies showed any tendency to return to baits they had experienced before. On day 1 we trapped $D$. subobscura using banana bait, marked them 
with red dust, and released them. On day 2 we trapped again at the same site using both banana and malt baits to see whether the marked flies, which had experienced banana, would make up a greater proportion of the catch on banana than on malt. The banana trapped flies were again marked with red dust, the malt trapped flies with blue dust, and both were released at the trapping site. On day 3 we again trapped with banana and malt bait to see whether red marked flies would return to banana and blue marked flies to malt.

The discreteness of morning and evening populations of $D$. subobscura was investigated during July 1979. Flies were trapped during three different time periods, 05.00-09.00 hours (G.M.T.), 10.00-14.00 hours, and 15.0019.00 hours. The flies were kept in vials containing food, and after the last trapping period were marked with three different coloured dusts according to their time of capture, and released. On the next day flies were again trapped throughout the day and examined for marks.

\section{Results}

The results of three of the four tests of individual habitat choice which were not significantly different from one another (Heterogeneity $\chi^{2}=3 \cdot 35$, d.f. $=2, \mathrm{P}>0.05)$, are combined in table 1 . In this table flies captured or recaptured in the lighter, open sites, $\mathrm{B}$ or $\mathrm{D}$, are contrasted with those from the dark, closed canopy sites, A or $\mathrm{C}$. The contingency $\chi^{2}$ shows that there is no tendency for $D$. subobscura to return to its area of first capture. Flies caught in either open or closed habitats distribute themselves in the same way.

In order to confirm that this result represented a genuine absence of habitat choice in this population it was important to demonstrate that the

\section{TABLE 1}

Number of $\mathrm{D}$. subobscura recaptured in light habitats $(B$ and $D)$ and dark habitats $(A$ and $C)$ classified according to their area of capture. Trapping occasions: May 1978, September 1978, fuly 1979

\begin{tabular}{|c|c|c|c|}
\hline \multirow{2}{*}{\multicolumn{2}{|c|}{ juy 100}} & \multicolumn{2}{|c|}{ Capture area } \\
\hline & & Light & Dark \\
\hline Recapture area & $\left\{\begin{array}{l}\text { Light } \\
\text { Dark }\end{array}\right.$ & $\begin{array}{l}36 \\
52\end{array}$ & $\begin{array}{l}41 \\
60\end{array}$ \\
\hline
\end{tabular}

TABLE 2

Number of $\mathrm{D}$. subobscura trapped in the different habitats during the habitat choice experiments

$\begin{array}{lccc} & \text { Site } & \text { A } & \text { B } \\ \text { May 1978 } & & 231 & 118 \\ & \text { Site } & \text { C } & \text { D } \\ \text { June 1978 } & & 786 & 417 \\ \text { September 1978 } & & 1566 & 788\end{array}$


Drosophila could distinguish between habitats. The number of flies captured in each habitat was recorded during the mark-release-recapture exercises, to see if species composition or abundance was significantly different between the sites. In all cases $D$. subobscura so dominated the collections that species composition could not sensibly be compared between sites. However, the numbers of $D$. subobscura captured in the different sites is shown in table 2 . On each occasion the darker site ( $A$ or $\mathrm{C}$ ) yielded about twice as many flies as the lighter one (B or $\mathrm{D})$. This evidently reflects a preference, and hence an ability to discriminate on the part of the flies. Otherwise dispersal rates should be fast enough to even out the differences between sites.

The results of the mark-release-recapture for June 1978, when the baits were swapped between capture and recapture, are given in table 3 . This time there is significant avoidance of site of first capture. Flies originally caught in habitat $\mathrm{C}$ tend to return to habitat $\mathrm{D}$ and vice versa. Because the baits were swapped the flies are, in fact, returning to the bait on which they were first captured. One explanation is that the flies remember a good feeding or breeding site from the previous day, and tend to return to the

\section{TABle 3}

Number of $\mathrm{D}$. subobscura recaptured in habitats $C$ and $D$ classified according to their area of capture. Trapping occasion: June 1978

Recapture area $\left\{\begin{array}{lcc}\mathrm{C} & \mathrm{D} \\ \mathrm{D} & 23 & 22 \\ 37 & 15 \\ \chi^{2}=4 \cdot 11, \text { d.f. }=1, \mathrm{P}<0.05\end{array}\right.$

TABLE 4A

Number of experienced (previously captured on banana) and inexperienced $\mathrm{D}$. subobscura caught on banana and malt baits

\begin{tabular}{|c|c|c|}
\hline & \multicolumn{2}{|c|}{ Bait } \\
\hline & Banana & Malt \\
\hline Experienced & 24 & 7 \\
\hline Inexperienced & 110 & 82 \\
\hline
\end{tabular}

$$
\chi^{2}=4 \cdot 51, \text { d.f. }=1, \mathrm{P}<0.05
$$

TABLE 4B

Number of $\mathrm{D}$. subobscura captured on banana or malt baits classified according to the bait on which they were recaptured

\begin{tabular}{|c|c|c|c|}
\hline & \multicolumn{2}{|c|}{ Capture bait } \\
\hline & & Banana & Malt \\
\hline Recapture bait & $\left\{\begin{array}{l}\text { Banana } \\
\text { Malt }\end{array}\right.$ & $\begin{array}{l}14 \\
14\end{array}$ & $\begin{array}{r}11 \\
8\end{array}$ \\
\hline
\end{tabular}

$\chi^{2}=0.28$, d.f. $=1$, not significant 
same smell even when it comes from a different location. Quinn, Harris and Benzer (1974) have shown that Drosophila melanogaster can learn to discriminate between olfactory cues, and that this conditioning can persist for 24 hours. Feeding or breeding site fidelity, which would have important ecological and genetic consequences (Lack, 1933; Dethier, 1954; MaynardSmith, 1970) might, then be a possibility. This is reinforced by the results in table $4 \mathrm{a}$ which show that there is a significantly greater tendency for flies which had experienced banana to return to banana compared with inexperienced flies. Table $4 \mathrm{~b}$ shows the number of $D$. subobscura marked on banana or malt which were recaptured on banana or malt. On this occasion, however, there was no tendency for the flies to return to the bait on which they were first captured. The existence of a phenomenon of feeding or breeding site fidelity remains a possibility but the results so far are highly equivocal.

TABLE 5

Number of D. subobscura captured in three different time periods during day 1 classified according to their time of recapture on day 2

\begin{tabular}{|c|c|c|c|c|}
\hline & & & ime of captu & \\
\hline & & $05.00-09.00$ & $10.00-14.00$ & $15.00-19.00$ \\
\hline & $(05.00-09.00$ & 6 & 0 & 20 \\
\hline Time of recapture & $\left\{\begin{array}{l}10.00-14.00 \\
\text { S }\end{array}\right.$ & 0 & 1 & 5 \\
\hline & $15.00-19.00$ & 6 & 7 & 29 \\
\hline
\end{tabular}

The results of the experiments on time-period selection are presented in table 5. There is no tendency for flies to be recaptured more frequently in the time period in which they were captured on the previous day. The morning and evening activity periods do not, then, consist of separate populations, but merely reflect the two most favourable times of day for activity.

\section{Discussion}

Before discussing any differences between $D$. subobscura and the North American obscura group species we must determine whether our failure to demonstrate habitat choice arises from any differences between our methods and those of Taylor and Powell (1978). The different habitats at Adel Dam average about half the size of those at Mather, California, and it might be argued that in a mosaic of smaller microhabitats, which the flies can cross in minutes, there is less opportunity for microgeographic differentiation to evolve. On the other hand, since dispersal rates are much lower in $D$. subobscura than in $D$. persimilis or $D$. pseudoobscura we consider that the habitats in Adel Dam and Mather would be perceived by their respective species of Drosophila as being of roughly the same size. Another possibility is that we might have failed to provide a sufficient contrast between habitats to detect individual habitat choice. We have, however, demonstrated that the flies can discriminate between the habitats at Adel, and Taylor and Powell (1978) were consistently able to detect habitat choice between dry and wet woods, descriptions of which (Taylor and 
Powell, 1977) do not suggest a greater contrast than between our pairs of habitats.

We feel that there are genuine differences between $D$. subobscura and the American species which might reflect differences between the genetics or ecology of the species. A failure to demonstrate habitat choice does not, of course, show that there is no genetic variation between habitats because genetic differences between habitats might be maintained by selection. It is worthwhile, however, to examine the evidence for microgeographic variation in D. subobscura. The results of Krimbas and Alevizos (1973) are difficult to interpret. No variation in allozyme frequencies was detected, and the variation in chromosome arrangements between sites was rather swamped by the sampling variance. At best the evidence for microgeographic genetic differentiation is less convincing than that for $D$. persimilis.

Obviously there are many differences between $D$. subobscura and $D$. persimilis in their ecology and genetics, and it is probably premature to try to account for the lack of habitat choice in $D$. subobscura. The results are, however, consistent with the well known inflexibility of the chromosome polymorphism in D. subobscura (Kunze-Mühl, Müller and Sperlich, 1958; Krimbas, 1967; Sperlich and Feuerbach, 1967; Krimbas and Alevizos, 1973), which seems relatively little affected by environmental or seasonal changes. Several authors have drawn attention to the contrast with the polymorphic 3rd chromosome of $D$. pseudoobscura and $D$. persimilis (Dobzhansky, 1962; Anderson, Dobzhansky and Kastritsis, 1967; Krimbas, 1967) which shows striking seasonal and altitudinal changes in inversion frequency. Organisms with flexible polymorphisms such as $D$. pseudoobscura are thought to adapt to heterogeneous environments by seasonal or habitat variations in the polymorphism (Dobzhansky, 1962), while those like $D$. subobscura with rigid polymorphisms have evolved a more generalised genotype which confers high fitness in a range of different environments. Our failure to demonstrate individual habitat choice in $D$. subobscura is, therefore, consistent with its genetic status. Such a species, with a generalised genotype, would not be expected to return to the habitat in which it was first captured. Conversely, $D$. persimilis and $D$. pseudoobscura are expected to be adapted to the environment in which they were found and so should return to that habitat, or a similar one, when removed.

Acknowledgments.-We would like to thank Dr B. Shorrocks for his help and advice, and Professor A. Robertson and Dr C. Taylor for their helpful comments on the manuscript. The work was supported by a Natural Environment Research Council grant to J. A. M.

\section{REFERENCES}

ANDERSON, w. W., DOBZhaNSKY, TH., AND KASTRITSIs, G. D. 1967. Selection and inversion polymorphism in experimental populations of Drosophila pseudoobscura initiated with the chromosomal constitutions of natural populations. Evolution, 21, 664-671.

BEgon, M. 1976. Dispersal, density and microdistribution in Drosophila subobscura Collin. 7. Anim. Ecol., 45, 441-456.

Begon, M. 1977. The effective size of a natural Drosophila subobscura population. Heredity, 38, 13-18.

BEgon, M. 1978. Population densities in Drosophila obscura Fallen and D. subobscura Collin. Ecol. Entomol., 3, 1-12.

CRUMPACKer, D. W., AND Williams, J. s. 1973. Density, dispersion and population structure in Drosophila pseudoobscura. Ecol. Monogr., 43, 499-538. 
DETHIER, v. G. 1954. Evolution of feeding preferences in phytophagous insects. Evolution, $8,33-54$.

DoBzhansky, тH. 1962. Rigid vs. flexible chromosomal polymorphisms in Drosophila. Amer. Nat., 96, 321-328.

DOBZHANSKY, TH., AND POWELL, J. R. 1974. Rates of dispersal in Drosophila pseudoobscura and its relatives. Proc. Roy. Soc. Lond. B, 187, 281-298.

Dyson-Hudson, v. R. D. 1956. The daily activity rhythm of Drosophila subobscura and $D$. obscura. Ecology, 37, 562-567.

hovanitz, w. 1953. Polymorphism and evolution. Symp. Soc. Exp. Biol., 7, 238-253.

KRIMBAs, C. B. 1967. The genetics of Drosophila subobscura populations. III. Inversion polymorphism and climatic factors. Molec. Gen. Genetics, 99, 133-150.

krimgas, C. B., AND ALEvizos, v. 1973. The genetics of Drosophila subobscura populations. IV. Further data on inversion polymorphism in Greece-Evidence of microdifferentiation. Egypt. 7. Genet. Cytol., 2, 121-132.

KUNZE-MÜHL, E., MÜLLER, E., AND SPERLICH, D. 1958. Qualitative, quantitative und jahreszeitliche Untersuchungen über den chromosomalen Polymorphismus natürlicher Populationen von Drosophila subobscura Coll in der Unigebung von Wien. Z. Vererbungsl., $89,636-646$.

LACK, D. 1933. Habitat selection in birds with special reference to the effects of afforestation on the breckland avifauna. 7. Anim. Ecol., 2, 239-262.

MaYNard-smith, J. 1970. Genetic polymorphism in a varied environment. Amer. Nat., 104, 487-490.

MITCHELL, D. F., AND EPLING, C. 1951. The diurnal periodicity of Drosophila pseudoobscura in Southern California. Ecology, 32, 696-708.

POWELL, J. R., DOBZHANSKy, TH., HOOK, J., AND WistRand, H. 1976. Genetics of natural populations. XLIII. Further studies on rates of dispersal of Drosophila pseudoobscura and its relatives. Genetics, 82, 493-506.

QUNN, w. G., HARRIS, w. A., AND BENZER, s. 1974. Conditioned behaviour in Drosophila melanogaster. Proc. Nat. Acad. Sci. U.S.A., 71, 708-712.

sHORRocks, в. 1975. The distribution and abundance of woodland species of British Drosophila (Diptera : Drosophilidae). 7. Anim. Ecol., 44, 851-864.

SPERLICH, D., AND FEUERBACH, H. 1967. Ist der chromosomale Strukturpolymorphismus von Drosophila subobscura stabil oder flexibel? Z. Vererbungsl., 98, 16-24.

TAYLOR, C. E. 1975. Genetic loads in heterogeneous environments. Genetics, 80, 621-635.

TAYLOR, C. E., AND POWELL, J. R. 1977. Microgeographic differentiation of chromosomal and enzyme polymorphisms in Drosophila persimilis. Genetics, 85, 681-695.

TAYLOR, C. E., AND POWELL, J. R. 1978. Habitat choice in natural populations of Drosophila. Oecologia (Berl.), 37 69-75. 